\title{
Iron Deficiency and Nonscarring Alopecia in Women: Systematic Review and Meta-Analysis
}

\author{
Yulia Treister-Goltzman a, b Shaked Yarza ${ }^{c}$ Roni Pelega, ${ }^{a}$ \\ ${ }^{a}$ Department of Family Medicine and Siaal Research Center for Family Practice and Primary Care, Faculty of Health \\ Sciences, Ben-Gurion University of the Negev, Beer-Sheva, Israel; ${ }^{b}$ Clalit Health Services, Beer-Sheva, Israel; \\ ${ }^{c}$ Clinical Research Center, Soroka University Medical Center, Beer-Sheva, Israel
}

\section{Keywords}

Iron deficiency $\cdot$ Nonscarring alopecia $\cdot$ Systematic review .

Meta-analysis

\begin{abstract}
Background: There is no clear-cut evidence in the existing medical literature of an association between iron deficiency and nonscarring alopecia. Objective: The objective of the study was to conduct a systematic review of the medical literature on the prevalence of iron deficiency in women with nonscarring alopecia and compare their ferritin levels with those of women without this condition. Methods: The electronic databases PubMed, Scopus, and Web of Science were searched between June 15, 2019, and July 24, 2019. Studies that evaluated the prevalence of iron deficiency in women with nonscarring alopecia and/or compared ferritin levels in women with and without this condition were entered into the meta-analysis. Thirty-six of 928 identified studies entered the systematic meta-analysis. The meta-analysis was performed using the random-effects method. Results: The overall number of participants was 10,029. The prevalence of ferritin levels from 10 to $15 \mathrm{ng} / \mathrm{dL}$ and below was $21 \%(12 ; 29)$. Women with nonscarring alopecia had lower ferritin values at $\mathrm{MD}=-18.51 \mathrm{ng} / \mathrm{dL}(-25.85 ;-11.16, p<0.01)$. Conclusion: Women with hair loss can benefit from higher ferritin levels.

(c) 2021 The Author(s).

Published by S. Karger AG, Basel

karger@karger.com www.karger.com/sad

Karger $\stackrel{\text { ' }}{5}$

GOPEN ACCESS

(C) 2021 The Author(s).

Published by S. Karger AG, Basel

This article is licensed under the Creative Commons Attribution 4.0 International License (CC BY) (http://www.karger.com/Services/ OpenAccessLicense). Usage, derivative works and distribution are permitted provided that proper credit is given to the author and the original publisher.
\end{abstract}

\section{Introduction}

Scalp hair has psychological and social effects on women. Loss of hair leads to impaired quality of life and social functioning $[1,2]$. There are many causes of hair loss, but a small number comprises the majority of relevant diagnoses [3] and the focus of the clinical work-up. All types of hair loss are categorized into 2 large groups: scarring and nonscarring alopecia. The most prevalent disorders of hair loss belong to the nonscarring group including telogen effluvium (acute and chronic TE), androgenetic alopecia, which is usually female pattern hair loss, and the less prevalent alopecia areata. The diagnosis of type of hair loss disorder is reached by history taking, physical examination, and tests such as the pull test and the trichogram. Opinions differ as to an association between iron deficiency/iron-deficiency anemia and hair loss in all 3 prevalent types. Some studies found significantly low ferritin levels in patients with nonscarring alopecia, while others did not $[2,4,5]$. In any event, it is a common practice among dermatologists and family doctors to conduct blood tests for patients with nonscarring alopecia including a complete blood count and ferritin level $[5,6]$. The aim of this study was to conduct a systematic search of the medical literature on a potential association between iron deficiency and nonscarring alopecia in women, and to base a meta-analysis on the identified studies that met the inclusion and exclusion criteria.

Correspondence to:

Yulia Treister-Goltzman, yuliatr@walla.com 


\section{Search Strategy for Identification of Studies}

The electronic databases PubMed, Scopus, and Web of Science were searched between January 15, 2020, and February 18, 2020, for studies on the association between iron deficiency and nonscarring alopecia in women. The search was not limited by date or language of publication. Two investigators (Y.T.G. and R.P.) conducted the search for relevant studies. The search was conducted in 2 steps with the keywords: alopecia and iron deficiency, hair loss and iron deficiency, and telogen effluvium and iron deficiency.

The inclusion criteria were as follows: (a) original research, (b) the study assessed either the prevalence of iron deficiency/iron-deficiency anemia or compared ferritin levels between women with and without hair loss, and (c) the study population was comprised of women. The exclusion criteria were as follows: (a) the study population was men, children, or mixed, (b) the terms iron deficiency and iron-deficiency anemia were not defined in the paper, (c) the study reported low hemoglobin levels without ferritin levels, and (d) the study participants were recruited from a population suffering from specific conditions or diseases such as patients after bariatric surgery or cancer patients.

In the first phase, the investigators reviewed the abstracts, and in the second selected full articles and bibliographic lists. If a full paper could not be obtained through the electronic database system, the authors communicated with the authors or requested the full article through ResearchGate. All papers were reviewed independently by the 2 investigators who determined whether to include the paper. In case of disagreement, the final decision was reached by consensus.

\section{Data Collection}

The data collected were as follows: authors and year of publication, type of study, sample size for statistical analyses, number of women in case-control studies (if relevant), the mean age and ethnic origin of the women, the type of hair loss, the method of diagnosis, and the measures of iron deficiency.

\section{Risk of Bias for the Included Studies}

The Newcastle-Ottawa scale is a simple, convenient tool for the quality assessment of nonrandomized studies. It uses a star system and is based on 4 domains: selection, comparability, exposure, and outcome. There are adapted versions for case-control and cohort studies [7]. We further adapted the Newcastle-Ottawa scale for our specific study purpose. The risk of bias assessment was conducted by 2 investigators in a blinded process, and in cases of disagreement, a consensus-reaching process was used.

\section{Data Synthesis and Analysis}

Meta-analyses were performed using the Metafor, Meta, and Demtar [8, 9] packages for $\mathrm{R}$ software (version 3.6.1) [10]. The prevalence rates for ferritin deficiency and iron-deficiency anemia were calculated from cohort and case-control studies using the inverse-variance weighting method.

Ferritin level below the range of 10-15 ng/dL was considered as ferritin deficiency $[5,11]$. Several studies have found that ferritin levels below 30-40 ng/dL are more sensitive and as specific for the diagnosis of iron deficiency [5]. A separate meta-analysis was performed on studies that used this cutoff level. The mean difference in ferritin levels between patients and controls was calculated in case-control studies using the inverse-variance method. The mean difference in ferritin levels was calculated separately for studies, in which participants were of childbearing age or premenopausal women. A $p$ value $<0.05$ was considered statistically significant.

In studies where the results were given in median (range), they were converted to mean (SD) by the method described by Hozo et al. [12]. In studies where the results were presented in mean and 95\% confidence intervals, they were converted to mean (SD) using the Cochrane Handbook for Systematic Reviews of Interventions [13]. The meta-analysis was performed using the random-effects model because a significant heterogeneity of the included studies was expected. The inconsistency index $\left(I^{2}\right)$ test and Cochran's Q were used to assess heterogeneity across studies. A value above $50 \%$, or $p<0.05$, indicated statistically significant heterogeneity. Additional meta-analyses were performed, excluding outliers. When significant heterogeneity was detected, funnel plots, Egger linear regression tests, and trim-and-fill methods were used to explore for publication bias. Influence analyses using the leave-one-out method were performed to identify if 1 specific study overly distorted the pooled effect size or overall heterogeneity.
Treister-Goltzman/Yarza/Peleg 
Fig. 1. Flowchart of the review process.

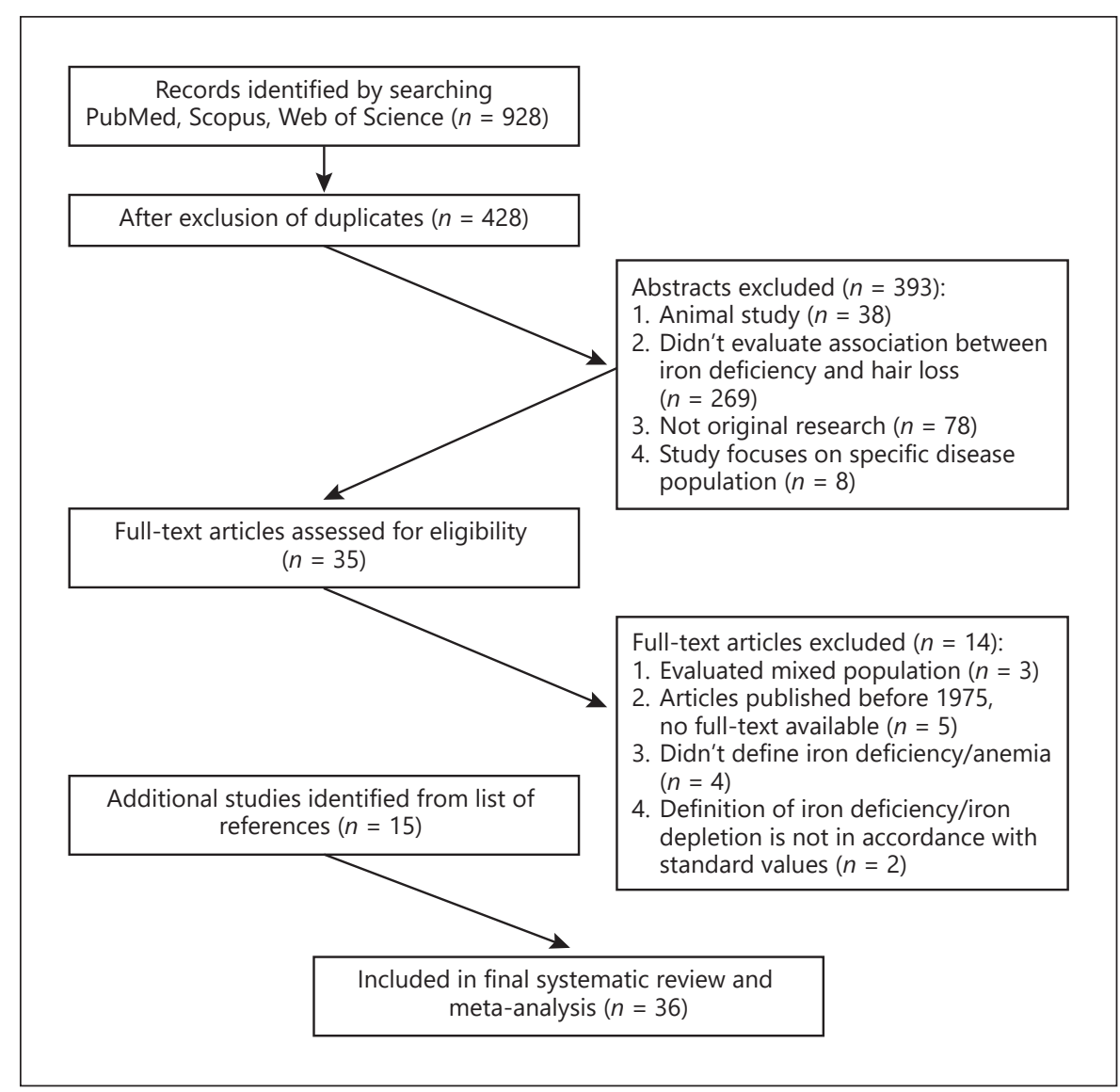

\section{Results}

We identified 928 studies in the electronic databases using all the search terms (see Search Strategy section). Of these, 500 were duplicates. Four hundred and twentyeight abstracts and names of articles were reviewed in phase 1 of the selection process. In phase 2 , we evaluated 35 full-text articles. The articles were obtained through the electronic library of Ben-Gurion University of the Negev. One article was received by request through ResearchGate. Two articles were received directly from the authors by email request. At the end of the process, 36 studies were entered into the systematic review and metaanalysis. The selection process is shown in the flowchart (shown in Fig. 1).

\section{Study Characteristics}

The characteristics of the studies that were included in the meta-analysis are described in Table 1. Twenty-one were case-control studies, and 15 were cohort studies. The year of publication ranged from 1988 to 2019. One study was published in German [14], 2 in Turkish [15, 16], and the rest in English. Articles published in languages other than English were addressed using language translation agency.

The variance in sample size was large. The total number of participants was 10,029. Of these, 6,641 suffered from alopecia and 3,388 were in the control group.

The mean age of the participants ranged between 23 and 44.4 years. The countries included 7 each from India and Turkey, 4 from Egypt, 3 from the UK, 2 each from Iran and the USA, and 1 each from Switzerland, China, France, Saudi Arabia, Australia, Germany, Korea, Bangladesh, Jordan, and Nepal.

Fifteen studies evaluated the prevalence of ferritin deficiency with the accepted threshold of 10-15 ng/dL, 24 the prevalence of ferritin levels below 30-40 ng/dL, and 5 the prevalence of iron-deficiency anemia. Eighteen studies compared mean ferritin levels between patient and control groups, and 16 involved premenopausal women/ women of childbearing age or included a subgroup of these women, which was clearly defined in the article. 


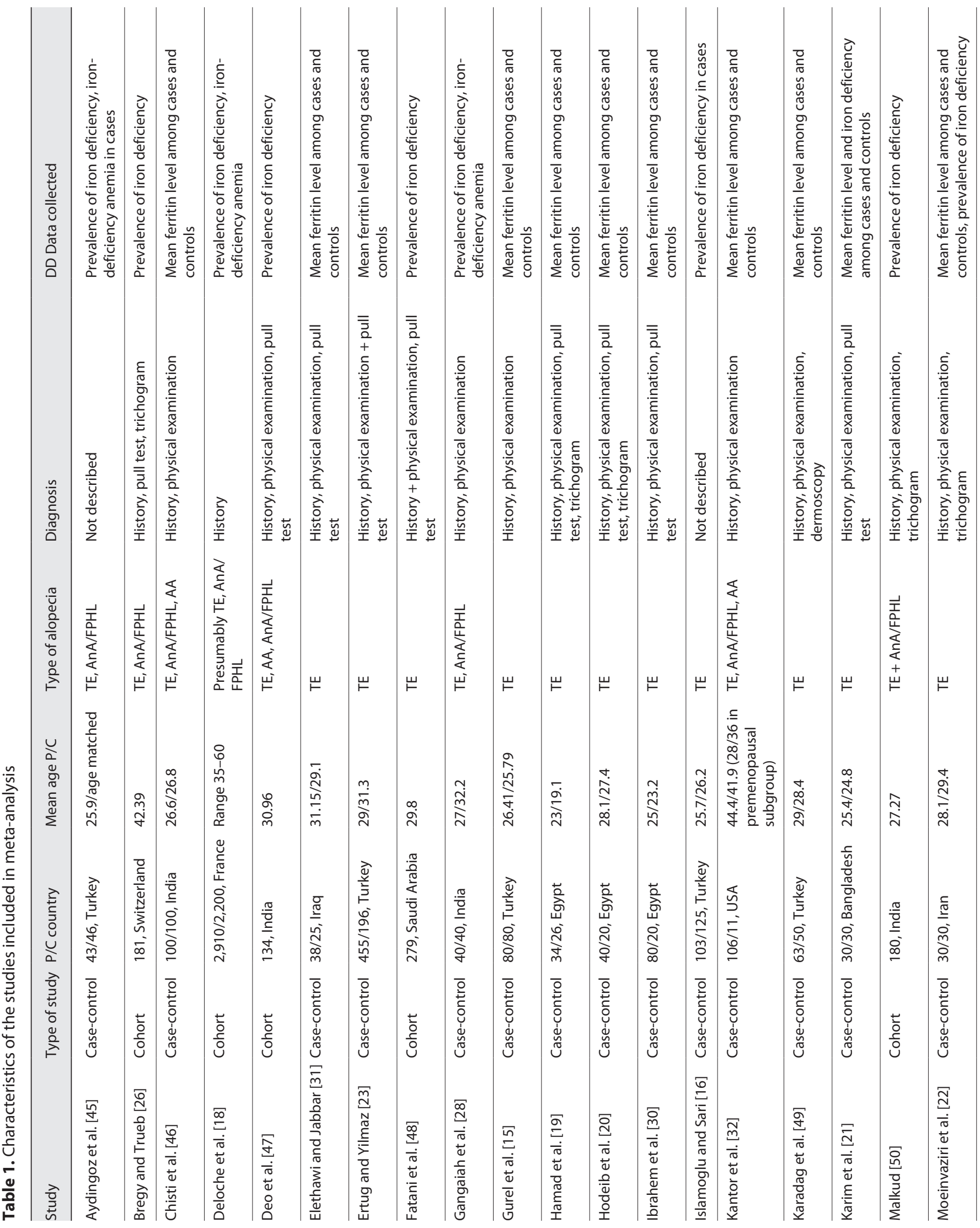




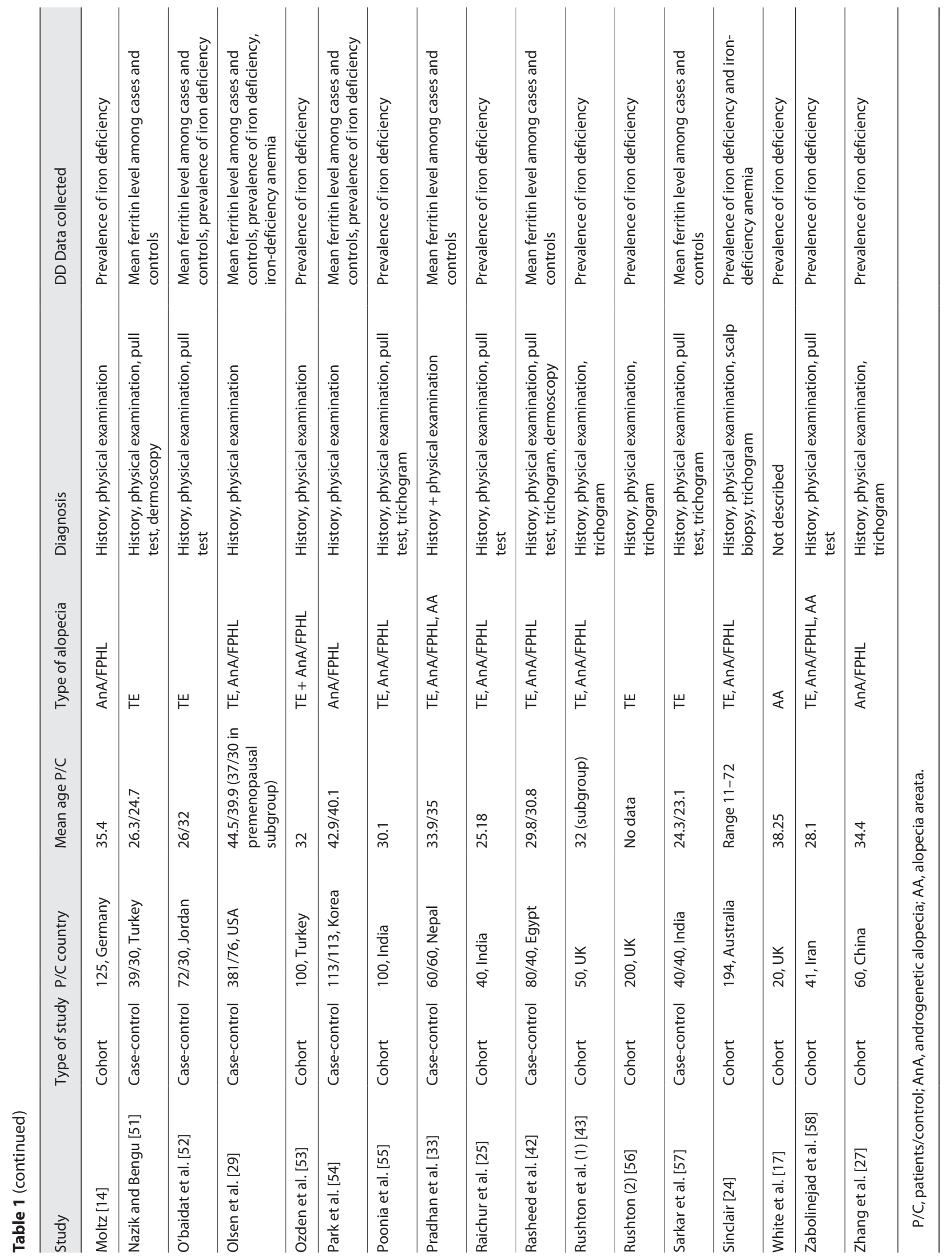


Fig. 2. Forest plot of the prevalence of iron deficiency.

Fig. 3. Forest plot of the difference in mean ferritin values between patients and controls.

\section{Study \\ Weight Prevalence, $95 \% \mathrm{Cl}$}

Aydingoz (1999)[45]

Bregy (2008)[26]

Deloche (2007)[18]

Deo (2016)[47]

$6.1 \%$

$7.3 \%$

$7.4 \%$

$7.3 \%$

Gangaiah (2019)[28] $\quad 6.1 \%$

Malkud (2015)[50] 6.9\%

Moienvaziri (2009)[22] 5.6\%

Olsen (2010)[29] $\quad 7.4 \%$

Park (2013)[54] 7.0\%

Poonia (2018)[55] $\quad 7.0 \%$

Raichur (2017)[25] $5.9 \%$

Sinclair (2002)[24] $\quad 7.4 \%$

White (1994)[17] $\quad 4.8 \%$

Zabolinejad (2017)[58] $\quad 6.7 \%$

Zhang (2012)[27]

$7.1 \%$

$0.33[0.19 ; 0.49]$

$0.08[0.04 ; 0.13]$

$0.19[0.18 ; 0.20]$

$0.07[0.03 ; 0.12]$

$0.28[0.15 ; 0.44]$

$0.30[0.21 ; 0.39]$

$0.33[0.17 ; 0.53]$

$0.09[0.06 ; 0.12]$

$0.20[0.13 ; 0.29]$

$0.20[0.13 ; 0.29]$

$0.57[0.41 ; 0.73]$

$0.03[0.01 ; 0.06]$

$0.50[0.27 ; 0.73]$

$0.10[0.03 ; 0.24]$

$0.07[0.02 ; 0.16]$

Random Effect $\quad 100.0 \% \quad 0.21$ [0.12; 0.29]

Heterogeneity: $R^{2}=95 \%, \tau^{2}=0.0224, \chi_{14}^{2}=261.99(p<0.01)$

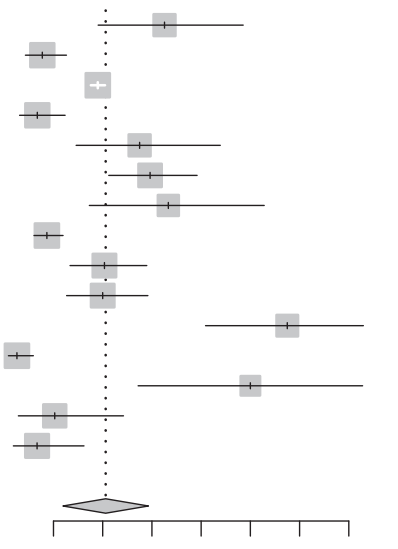

$\begin{array}{lllllll}0.1 & 0.2 & 0.3 & 0.4 & 0.5 & 0.6 & 0.7\end{array}$

\begin{tabular}{|c|c|c|c|c|}
\hline Study & Weight & $\begin{array}{c}\text { Mean Difference } \\
\text { IV, Random, 95\% CI }\end{array}$ & \multicolumn{2}{|c|}{ Mean Difference } \\
\hline $\begin{array}{l}\text { Chisti }(2012)[46] \\
\text { Elathawi (2012)[31] } \\
\text { Ertug (2018)[23] } \\
\text { Gurel (2017)[15] } \\
\text { Hamad (2010)[19] } \\
\text { Hodeib }(2017)[20] \\
\text { Ibrahem }(2012)[30] \\
\text { Kantor }(2003)[32] \\
\text { Karadag (2011)[49] } \\
\text { Karim (2010)[21] } \\
\text { Moienvaziri (2009)[22 } \\
\text { Nazik (2019)[51] } \\
\text { Obaidat (2005)[52] } \\
\text { Olsen (2010)[29] } \\
\text { Park (2013)[54] } \\
\text { Pradhan (2018)[33] } \\
\text { Rasheed (2013)[42] } \\
\text { Sarkar (2013)[57] }\end{array}$ & $\begin{array}{l}6.2 \% \\
5.9 \% \\
6.3 \% \\
6.2 \% \\
5.9 \% \\
4.1 \% \\
4.5 \% \\
6.3 \% \\
5.7 \% \\
6.3 \% \\
2.4 \% \\
6.3 \% \\
3.3 \% \\
5.6 \% \\
5.1 \% \\
6.4 \% \\
6.0 \% \\
5.4 \%\end{array}$ & $\begin{array}{r}-7.40[-12.25 ;-2.55] \\
-23.60[-31.62 ;-15.58] \\
-21.92[-26.38 ;-17.46] \\
-9.66[-14.85 ;-4.48] \\
-54.96[-63.08 ;-46.84] \\
-14.82[-35.06 ; 5.42] \\
-23.30[-41.06 ;-5.54] \\
-19.60[-23.03 ;-16.17] \\
-17.10[-26.58 ;-7.62] \\
-17.80[-22.38 ;-13.22] \\
-44.00[-62.49 ;-25.51] \\
-12.46[-16.32 ;-8.60] \\
-28.90[-55.62 ;-2.18] \\
10.99[0.28 ; 21.70] \\
-28.62[-42.23 ;-15.01] \\
-3.46[-6.28 ;-0.64] \\
-22.10[-29.39 ;-14.81] \\
-6.60[-18.34 ; 5.14]\end{array}$ & 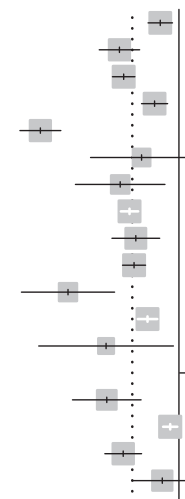 & + \\
\hline Random Effect 1 & $100.0 \%$ & $-18.51[-25.85 ;-11.16]$ & $\dot{\theta}$ & \\
\hline $\begin{array}{l}\text { Heterogeneity: } R^{2}=93 \\
\text { Test for overall effect: }\end{array}$ & $\begin{array}{l}3 \%, \mathrm{\tau}^{2}=1 \\
\mathrm{t}: t_{17}=-5\end{array}$ & $\begin{array}{l}.4153, \chi_{17}^{2}=236.56(p<0.01) \\
(p<0.01)\end{array}$ & $\begin{array}{ccc} & 1 & 1 \\
-60 & -40 & -20\end{array}$ & \begin{tabular}{l|ll} 
& 1 & \\
20 & $40 \quad 6$
\end{tabular} \\
\hline
\end{tabular}

\section{Outcomes}

Prevalence of Ferritin Deficiency

The prevalence of ferritin deficiency was $21 \%(12 ; 29)$, with significant heterogeneity among the studies $\left(I^{2}=\right.$ $95 \%, p<0.01)$. A forest plot of the prevalence of iron deficiency is shown in Figure 2. When outliers were excluded from analysis from the subgroups, the prevalence of iron deficiency changed to $19 \%(12 ; 26)$. An "influence analysis" was carried out, omitting each of the studies individually without any significant effect on the prevalence of iron deficiency. A funnel plot showed no evidence for publication bias by Egger's regression test, in the studies that examined the prevalence of ferritin levels of 10-15 ng/dL and below $(p=0.42)$.

Online supplementary Figure 1 (for all online suppl. material, see www.karger.com/doi/10.1159/000519952) shows a forest plot of the prevalence of ferritin levels below the cutoff of 30-40 ng/dL among women with alopecia. It demonstrates the overall prevalence of ferritin levels below the cutoff of $59 \%\left(49 ; 69, I^{2}=98 \%\right.$, $p<0.01)$. Similarly, the outlier exclusion and influence analyses did not change the results of meta-analysis significantly. 
Fig. 4. Forest plot of the difference in mean ferritin values between patients and controls among premenopausal women.

\begin{tabular}{|c|c|c|c|c|}
\hline Study & Weight & $\begin{array}{c}\text { Mean Difference } \\
\text { IV, Random, 95\% CI }\end{array}$ & \multicolumn{2}{|c|}{ Mean Difference } \\
\hline $\begin{array}{l}\text { Chisti (2012)[46] } \\
\text { Elathawi (2012)[31] } \\
\text { Ertug }(2018)[23] \\
\text { Gurel }(2017)[15] \\
\text { Hamad (2010)[19] } \\
\text { Hodeib (2017)[20] } \\
\text { lbrahem }(2012)[30] \\
\text { Kantor (2003)[32] } \\
\text { Karim }(2010)[21] \\
\text { Moienvaziri (2009)[22 } \\
\text { Obaidat (2005)[52] } \\
\text { Olsen }(2010)[29] \\
\text { Park (2013)[54] } \\
\text { Pradhan (2018)[33] } \\
\text { Rasheed (2013)[42] } \\
\text { Sarkar (2013)[57] }\end{array}$ & $\begin{array}{l}7.1 \% \\
6.8 \% \\
7.1 \% \\
7.1 \% \\
6.8 \% \\
5.1 \% \\
5.5 \% \\
4.4 \% \\
7.1 \% \\
27.4 \% \\
4.2 \% \\
6.8 \% \\
6.4 \% \\
7.2 \% \\
6.9 \% \\
6.4 \%\end{array}$ & $\begin{array}{r}-7.40[-12.25 ;-2.55] \\
-23.60[-31.62 ;-15.58] \\
-21.92[-26.38 ;-17.46] \\
-9.66[-14.85 ;-4.48] \\
-54.96[-63.08 ;-46.84] \\
-14.82[-35.06 ; 5.42] \\
-23.30[-41.06 ;-5.54] \\
-39.82[-65.10 ;-14.54] \\
-17.80[-22.38 ;-13.22] \\
-44.00[-62.49 ;-25.51] \\
-28.90[-55.62 ;-2.18] \\
10.62[2.21 ; 19.03] \\
-38.65[-50.06 ;-27.24] \\
-3.46[-6.28 ;-0.64] \\
-22.10[-29.39 ;-14.81] \\
-6.60[-18.34 ; 5.14]\end{array}$ & 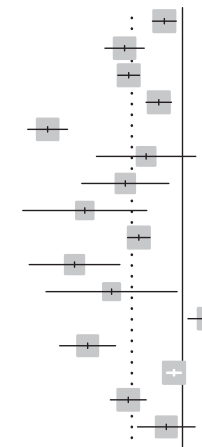 & + \\
\hline Random Effect & $100.0 \%$ & $-20.65[-29.74 ;-11.55]$ & $\dot{\infty}$ & \\
\hline $\begin{array}{l}\text { Heterogeneity: } R^{2}=94 \\
\text { Test for overall effect: }\end{array}$ & $\begin{array}{l}4 \%, \tau^{2}=2 \\
: t_{15}=-4 .\end{array}$ & $\begin{array}{l}.7941, \chi_{15}^{2}=254.07(p<0.01) \\
(p<0.01)\end{array}$ & 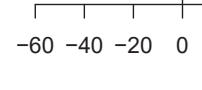 & $20 \quad 40 \quad 60$ \\
\hline
\end{tabular}

Prevalence of Iron-Deficiency Anemia $(\mathrm{Hb}<12 \mathrm{~g} /$ dL, Ferritin $<15$ ng/dL)

Five studies examined the prevalence of iron-deficiency anemia. The overall prevalence of iron-deficiency anemia in the meta-analysis was $8 \%(0 ; 21)$, with significant heterogeneity among the studies $\left(I^{2}=97, p<0.01\right)$ (shown in online suppl. Fig. 2). In the influence analysis, the prevalence varied from $5 \%$ to $11 \%$. There was no evidence for publication bias $(p=0.37)$ with either the funnel plot or Egger's regression test.

\section{Difference in Mean Ferritin Values between Patients and Controls}

Eighteen studies compared mean ferritin values between patients with nonscarring alopecia and controls. A forest plot of the meta-analysis is shown in Figure 3. When the studies were pooled, a statistically significant difference was seen, with the mean ferritin values lower in patients with alopecia at $\mathrm{MD}=-18.51 \mathrm{ng} / \mathrm{dL}(-25.85$; $-11.16 ; p<0.01)$ with significant heterogeneity among the studies $\left(I^{2}=93 \%, p<0.01\right)$. When outliers $[19,29,33]$ were excluded from the meta-analysis, a statistically significant difference in ferritin levels was still seen between the patients and controls at $\mathrm{MD}=-18.23 \mathrm{ng} / \mathrm{dL}(-22.93$; -13.53 ; $\left.p<0.01, I^{2}=74 \%, p<0.01\right)$. When the studies were omitted one at a time in the influence analyses, the difference in pooled MD between patients and controls was still statistically significant. Publication bias was not the source of heterogeneity $(p=0.15)$ as measured by funnel plot and Egger's test.

Iron Deficiency and Alopecia in Women
Difference in Mean Ferritin Levels between Patients and Controls of Childbearing Age/Premenopause

Sixteen studies dealt with premenopausal women/ women of childbearing age or included them as a subgroup. A forest plot of the meta-analysis is shown in Figure 4 . When the studies were pooled in the meta-analysis, a statistically significant difference was seen with lower mean ferritin levels in patients with alopecia $(\mathrm{MD}=$ $-20.65 \mathrm{ng} / \mathrm{dL}[-29.74 ;-11.55 ; p<0.01])$ with significant heterogeneity among the studies $\left(I^{2}=94 \%, p<0.01\right)$. A statistically significant difference in ferritin levels between the patients and controls was still found when outlier papers $[19,29,33]$ were omitted from the meta-analysis $\left(\mathrm{MD}=-21.11 \mathrm{ng} / \mathrm{dL}\left[-28.14 ;-14.08 ; p<0.01, I^{2}=\right.\right.$ $80 \%, p<0.01])$. Omitting study by study in influence analyses still resulted in a statistically significant difference in pooled MD between patients and controls. The funnel plot and Egger's test did not indicate that the source of heterogeneity was publication bias $(p=0.07)$.

\section{Risk of Study Bias}

The results of an adapted Newcastle-Ottawa scale for the risk of bias assessment of the included studies are shown in online supplementary Table 1 and 2 . Of 21 casecontrol studies, 14 were of good quality (7-8/9), 7 were of fair quality (5-6/9), and none was of poor quality. All 15 cohort studies were of good quality $(2 / 3)$. The main drawback in all but one of the studies was that they focused on populations from referral centers and tertiary care hospitals. 


\section{Discussion}

This meta-analysis that evaluated associations between iron deficiency and hair loss of the nonscarring type included studies from a broad range of countries from Europe, Asia, Africa, and the USA. The prevalence of iron deficiency, defined as a ferritin level between 10 and $15 \mathrm{ng} / \mathrm{dL}$ or below, was $21 \%$. This result is comparable with the prevalence of iron depletion in the general population. In Europe, the reported rates are from 3 to $8 \%$ in Poland and Italy to $22-23 \%$ in Norway, Belgium, and France $[34,35]$. The reported rate of iron deficiency in the USA and Canada is $10-12 \%$ [36]. The reported prevalence rate for iron deficiency from Asian countries is $20-26 \%$ and in different regions of Ethiopia $18-50 \%$ [37-41]. Based on these data, it would appear that ferritin deficiency in women with nonscarring alopecia is not higher than in the general population. Several studies suggested higher cutoff levels of below $30-40 \mathrm{ng} / \mathrm{dL}$ as the definition of iron deficiency $[5,29,42-44]$. This threshold of $30-41 \mathrm{ng} / \mathrm{dL}$ yields sensitivity and specificity rates of 92-98\% each for iron deficiency [29]. The prevalence of iron deficiency among women with hair loss increased with this threshold to 59\%. It would appear that the prevalence of reduced ferritin levels (below 30-40 ng/dL) is higher among women with diffuse hair loss than among women in the general population. Ferritin levels below 30 $\mathrm{ng} / \mathrm{dL}$ were found in $40-50 \%$ of the women in Denmark and Norway [34], 32\% of the women in Portugal [35], and $47 \%$ of the women in Cambodia [38].

The heterogeneity in the frequency of iron deficiency of varying degrees of severity can be explained easily by the different frequencies of iron deficiency in developing and developed countries and the difference in the ages of the participating women since the prevalence of iron deficiency decreases significantly in postmenopausal women. The overall prevalence of iron-deficiency anemia in our study was $8 \%$. The reported prevalence rates in Europe were lower at 2-6\% [34] than in 6-18\% in Nepal, Pakistan, and Ethiopia [37, 39, 40]. A comparison of the individual studies with the overall meta-analysis results shows that the rate of iron-deficiency anemia among women with hair loss is not higher than in the general population of women.

The main meta-analysis in the present study summarized case-control studies and compared ferritin levels between women with nonscarring alopecia and matched population controls. It demonstrated a statistically significant difference between the groups, which was even more striking when the analysis included only premenopausal women.

\section{Conclusion}

There is a significant difference in ferritin levels between women with nonscarring alopecia and healthy women. Iron-deficiency anemia is not more common among women with nonscarring alopecia. Thus, it would appear that women who complain of hair loss can benefit from higher ferritin levels.

\section{Acknowledgments}

This manuscript does not include any nonauthor contributors to acknowledge.

\section{Statement of Ethics}

Ethical approval was not required for this study in accordance with national guidelines.

\section{Conflict of Interest Statement}

The authors have no conflicts of interest to declare.

\section{Funding Sources}

This research did not receive any specific grant from funding agencies in the public, commercial, or not-for-profit sectors.

\section{Author Contributions}

Yulia Treister-Gotzman contributed to the conception of the research. Yulia Treister-Goltzman, Roni Peleg, and Shaked Yarza equally contributed to the design of the research. Yulia TreisterGoltzman and Roni Peleg equally contributed to the acquisition of the data. Yulia Treister-Goltzman and Shaked Yarza equally contributed to the analysis of the data. All authors contributed to the interpretation of the data. Yulia Treister-Goltzman and Shaked Yarza drafted the manuscript. All the authors critically revised the manuscript, agreed to be fully accountable for ensuring the integrity and accuracy of the work, and read and approved the final manuscript.

\section{Data Availability Statement}

All data generated or analyzed during this study are included in this article and its online supplementary material files. Further inquiries can be directed to the corresponding author.
Treister-Goltzman/Yarza/Peleg 


\section{References}

1 Harfmann KL, Bechtel MA. Hair loss in women. Clin Obstet Gynecol. 2015;58(1):185-99.

2 Malkud S. Telogen effluvium: a review. J Clin Diagn Res. 2015;9(9):WE01-3.

3 Kolivras A, Thompson C. Primary scalp alopecia: new histopathological tools, new concepts and a practical guide to diagnosis. $\mathrm{J} \mathrm{Cu}$ tan Pathol. 2017;44(1):53-69.

4 Redler S, Messenger AG, Betz RC. Genetics and other factors in the aetiology of female pattern hair loss. Exp Dermatol. 2017;26(6): 510-7.

5 Grover C, Khurana A. Telogen effluvium. Indian J Dermatol Venereol Leprol. 2013;79(5): 591-603.

6 Wolff H, Fischer TW, Blume-Peytavi U. The diagnosis and treatment of hair and scalp diseases. Dtsch Arztebl Int. 2016;113(21):37786.

7 Wells GA, Shea B, O'Connell D, Peterson J, Welch V, Losos M, et al. The Newcastle-Ottawa Scale (NOS) for assessing the quality of life and thyoid-related symptoms in patiens with subclinical hypothyroidism: to treat or not to treat, that is the question! A systematic review and meta-analysis. 2015. Available from: http: //www.ohri.ca/programs/clinical_epidemiology/oxford.asp.

8 Harrer M, Cuijpers P, Furukawa TA, Ebert DD. Doing meta-analysis in R: a hand-on guide. Boca Raton, FL and London: Chapmann \& Hall/CRC Press; 2021. Available from: https://bookdown.org/MathiasHarrer/ Doing Meta_Analysis in R/.

9 Schwarzer G, Carpenter JR, Rücker G. Metaanalysis with R. New York: Springer; 2015.

10 R Core Team. A language and environment for statistical computing. Vienna, Austria: R Foundation for Statistical Computing; 2019. Available from: http://www.r-project.org/index.html.

11 Daru J, Colman K, Stanworth SJ, De La Salle B, Wood EM, Pasricha SR. Serum ferritin as an indicator of iron status: what do we need to know? Am J Clin Nutr. 2017;106(Suppl 6): 1634S-9S.

12 Hozo SP, Djulbegovic B, Hozo I. Estimating the mean and variance from the median, range, and the size of a sample. BMC Med Res Methodol. 2005;5:13.

13 Higgins JP, Thompson SG. Controlling the risk of spurious findings from meta-regression. Stat Med. 2004;23:1663-82.

14 Moltz L. [Hormonal diagnosis in so-called androgenetic alopecia in the female] (German). Geburtshilfe Frauenheilkd. 1988;48: 203-14.

15 Gurel G, Karadol M, Colgecen E. The role of ferritin and vitamin D levles in telogen effluvium. Turkiye Klinikleri J Dermatol. 2017;27: 113-6

16 Islamoglu Z, Sari N. The association of ABO blood groups and serum ferritin levels with telogen effluvium in women. Ann Med Res. 2018;25(4):327-9.
17 White MI, Currie J, Williams MP. A study of the tissue iron status of patients with alopecia areata. Br J Dermatol. 1994;130:261-3.

18 Deloche C, Bastien P, Chadoutaud S, Galan P, Bertrais S, Hercberg S, et al. Low iron stores: a risk factor for excessive hair loss in nonmenopausal women. Eur J Dermatol. 2007; 17:507-12.

19 Hamad WAM, Said AF, Abd El Hamid A. Role of some trace elements in the pathogenesis of telogen effluvium in Egyptian females. J Egypt Women Dermatol Soc. 2010;7:44-8.

20 Hodeib AA, Neinaa YME, Mourad HA, Daba RAS. Role of iron in telogen effluvium among premenopausal women. Egypt J Dermatol Venereol. 2017;37:56-61.

21 Karim M, Wahab A, Khondoker L, Khan SI. Low iron level is related to telogen effluvium in women. Bangladesh J Med. 2010;21:84-9.

22 Moeinvaziri M, Mansoori P, Holakooee K, Safaee Naraghi Z, Abbasi A. Iron status in diffuse telogen hair loss among women. Acta Dermatovenerol Croat. 2009;17:279-84.

23 Ertug EY, Yilmaz RA. Reduced ferritin, folate, and vitamin B12 levels in female patients diagnosed with telogen effluvium. Int J Med Biochem. 2018;1:111-4.

24 Sinclair R. There is no clear association between low serum ferritin and chronic diffuse telogen hair loss. Br J Dermatol. 2002;147: 982-4.

25 Raichur S, Pandit A, Malleshappa A. Correlation of serum ferritin levels, in female patients with chronic diffuse hair loss: a cross sectional study. Indian J Health Sci Biomed Res. 2017;10(2):190-5.

26 Bregy A, Trueb RM. No association between serum ferritin levels $>10 \mu / \mathrm{L}$ and hair loss activity in women. Dermatology. 2008;217(1): $1-6$.

27 Zhang X, Caulloo S, Zhao Y, Zhang B, Cai Z, Yang J. Female pattern hair loss: clinico-laboratory findings and trichoscopy depending on disease severity. Int J Trichology. 2012;4:23-

28 Gangaiah N, Thimmappa V, Potlapati A, Gowda C. A case control study of relationship between body iron stores and non scarring diffuse hair loss in non menopausal women. Indian J Clin Exp Dermatol. 2019;5:80-4.

29 Olsen EA, Reed KB, Cacchio PB, Caudill L. Iron deficiency in female pattern hair loss, chronic telogen effluvium, and control groups. J Am Acad Dermatol. 2010;63:991-9.

30 Ibrahem MK, Abd-Elal EB, El Shahed AR, Maawad AN, El-Gendy AEA, Elsaie ML. Estimation of serum ferritin level in female patients with telogen effluvium. Hair Ther Transplant. 2012;2:2.

31 Elethawi AMD, Jabbar RI. Comparison between hemoglobin serum level and serum ferritin level in detecting low iron store in adult menstruating females with chronic telogen effluvium. Iraqi Postgrad Med J. 2012;11:8791.
32 Kantor J, Kessler LJ, Brooks DG, Cotsarelis G. Decreased serum ferritin is associated with alopecia in women. J Invest Dermatol. 2003, 121:985-8.

33 Pradhan M, Rai D, Paudel S. A study of serum ferritin level in female patient with alopecia. J Coll Med Sci Nepal. 2018;14:155-9.

34 Milman N, Taylor CL, Merkel J, Brannon PM. Iron status in pregnant women and women of reproductive age in Europe. Am J Clin Nutr. 2017;106(Suppl 6):1655S-62S.

35 Fonseca C, Marques F, Robalo Nunes A, Belo A, Brilhante D, Cortez J. Prevalence of anaemia and iron deficiency in Portugal: the EMPIRE Study. Intern Med J. 2016;46:470-8.

36 Gordeuk VR, Brannon PM. Ethnic and genetic factors of iron status in women of reproductive age. Am J Clin Nutr. 2017;106(Suppl 6):1594S-9S.

37 Chandyo RK, Strand TA, Ulvik RJ, Adhikari RK, Ulak M, Dixit H, et al. Prevalence of iron deficiency and anemia among healthy women of reproductive age in Bhaktapur, Nepal. Eur J Clin Nutr. 2007;61:262-9.

38 Marukat J, Friedrich H, Kuong K, Wieringa FT. Nutritional and micronutrient status of female workers in a garment factory in Cambodia. Nutrients. 2016;8:694.

39 Habib MA, Raynes-Greenow C, Soofi SB, Ali N, Nausheen S, Ahmed I, et al. Prevalence and determinants of iron deficiency anemia among non-pregnant women of reproductive age in Pakistan. Asia Pac J Clin Nutr. 2018;27: 195-203.

40 Haidar J. Prevalence of anaemia, deficiencies of iron and folic acid and their determinants in Ethiopian women. J Health Popul Nutr. 2010;28:359-68.

41 Gebreegziabher T, Stoecker BJ. Iron deficiency was not the major cause of anemia in rural women of reproductive age in Sidama zone, southern Ethiopia: a cross-sectional study. PLoS One. 2017;12:e0184742.

42 Rasheed H, Mahgoub D, Hegazy R, El-Komy M, Abdel Hay R, Hamid MA, et al. Serum ferritin and vitamin $\mathrm{d}$ in female hair loss: do they play a role? Skin Pharmacol Physiol. 2013;26:101-7.

43 Rushton DH, Ramsay ID, James KC, Norris MJ, Gilkes JJ. Biochemical and trichological characterization of diffuse alopecia in women. Br J Dermatol. 1990;123:187-97.

44 Rushton DH, Ramsay ID. The importance of adequate serum ferritin levels during oral cyproterone acetate and ethinyl oestradiol treatment of diffuse androgen-dependent alopecia in women. Clin Endocrinol. 1992;36:421-7.

45 Aydingoz IE, Ferhanoglu B, Guney O. Does tissue iron status have a role in female alopecia? J Eur Acad Dermatol Venereol. 1999; 13(1):65-7.

46 Chisti MA, Masood Q, Shah IH, Khan D, Majid I, Qayoom S, et al. Serum ferritin levels in non-scarring alopecia of women: a case-control study. J Pakistan Ass Dermatol. 2012;22: 4-11. 
47 Deo K, Sharma YK, Wadhokar M, Tyagi N. Clinicoepidemiological observational study of acquired alopecias in females correlating with anemia and thyroid function. Dermatol Res Pract. 2016;2016:6279108.

48 Fatani MI, Bin mahfoz AM, Mahdi AH, Alafif KA, Hussain WA, Khan AS, et al. Prevalence and factors associated with telogen effluvium in adult females at Makkah region, Saudi Arabia: a retrospective study. J Dermatology Dermatologic Surg. 2015;19:27-30.

49 Karadag AS, Ertugrul DT, Tutal E, Akin KO. The role of anemia and vitamin D levels in acute and chronic telogen effluvium. Turk J Med Sci. 2011;41:821-33.

50 Malkud S. A hospital-based study to determine causes of diffuse hair loss in women. J Clin Diagn Res. 2015;9:WC01-4.
51 Nazik H, Bengu AS. Evaluation of the levels of trace elements in the blood and hair of female patients with chronic telogen effluvium. Trace Elem Electroly. 2019;36:126-30.

52 O'baidat NA, Rawashdeh BT, Wreikat AA, Awamleh AA. A potential relation between telogen effluvium and iron deficiency in adult females. J R Med Serv. 2005;12:62-6.

53 Ozden MG, Oztas MO, Gukekon A, Gurer MA. Diffuse hair loss in females and associating findings. O M U J Exp Clin Med. 2008;25: 50-6.

54 Park SY, Na SY, Kim JH, Cho S, Lee JH. Iron plays a certain role in patterned hair loss. J Korean Med Sci. 2013;28:934-8.
55 Poonia K, Thami GP, Bhalla M, Jaiswal S, Sandhu J. Nonscarring diffuse hair loss in women: a clinico-etiological study from tertiary care center in North-West India. J Cosmet Dermatol. 2019;18:401-7.

56 Rushton DH. Nutritional factors and hair loss. Clin Exp Dermatol. 2002;27:396-404.

57 Sarkar P, Raghunatha H, Harish MR, Shashikumar BM. A case control study to determine the correlation between serum ferritin levels and chronic telogen effluvium in a tertiary hospital, Mandya. WebmedCentral Biochem. 2013;4:WMC004033.

58 Zabolinejad N, Hoseininejad M, Jannatipour $\mathrm{M}$, Layegh $\mathrm{P}$. The convergence between diagnostic methods in women with non-scarring hair loss. Iran J Dermatol. 2017;20:122-6. 